\title{
Measuring Voltage Balance Using a Switching Scheme
}

\author{
Svetlana Avramov-Zamurovic ${ }^{1}$, Brian Waltrip ${ }^{2}$, Andrew Koffman ${ }^{2}$ and George Piper ${ }^{1}$ \\ ${ }^{1}$ United States Naval Academy, Annapolis, Maryland, USA avramov@usna.edu \\ ${ }^{2}$ National Institute of Standards and Technology $y^{\dagger}$, Gaithersburg, Maryland, USA
}

\section{Introduction}

Most precise electrical impedance measurement procedures involve a voltage balance. A voltage balance is defined as the condition in which the difference between two voltages is driven to zero by independent injections. The uncertainty of the measured value directly depends on how close to zero the balance was driven in magnitude and phase. The uncertainty level required by current state-of-the art impedance experiments is on the order of $1 \times 10^{-6}$ (one part per million). Traditionally, voltage balance has been achieved by using inductive voltage dividers in a bridge configuration [1], [2]. The inductive voltage dividers are used because they can provide acceptable uncertainty. An attempt is made to explore the possibility of using electronics instead of inductive voltage dividers in a generalized bridge configuration.

This paper will describe in detail a measurement system that requires a precise voltage balance. The measurements involve a switching scheme that aides the iterative process of driving the voltage difference to zero. The mathematical model of the system will be described and the balance voltage derived. The validity of the assumptions will be checked using software simulation. This is preliminary work that requires experimental confirmation. Based on the results of the proposed algorithm an experiment may be planned in which the system will be constructed and the suggested measurement procedure tested.

In the Systems Engineering Department at the U.S. Naval Academy, we strongly emphasize capstone design projects. The proposed research presents a very good opportunity to teach students the full design cycle. This experiment is well defined using mathematical tools and in that sense it is a straightforward task to develop a software simulation. The actual construction of the measurement system is rather complex but students will benefit from using it once it has been completed. Making measurements to verify the model increases our understanding of the developed system.

\section{Measurement System}

In the field of precise measurements, it is often desired to balance voltage differences. In the example that will be presented in this paper, a generalized circuit that operates in the audio frequency range is given (see Fig. 1.) Voltages $V_{1}, V_{2} V_{3}$, and $V_{4}$ are node voltages derived from an impedance bridge. These voltages

\footnotetext{
${ }^{\dagger}$ Electronics and Electrical Engineering Laboratory, Technology Administration, U.S. Department of Commerce. Contribution of the U.S. Government. Not subject to copyright in the U.S.
} 
differ from each other by $1 \mathrm{~V}$ nominally, with voltage (magnitude and phase) variations on the order of 0.1 percent.

The goal is to balance $V_{1}-V_{2}=V_{3}-V_{4}$ with uncertainty on the order of one part per million. This balance can be measured by using differential amplifiers, but the accuracy (estimated from the manufacturer specification sheets) is not acceptable. The proposed solution utilizes operational amplifiers and a switching scheme. The purpose of the switching scheme is to allow redundant voltage measurements in order to better estimate the amplifier gain. The voltage residues are measured using a lock-in amplifier (balance indicator). The lock-in amplifier can precisely measure extremely small voltages (on the order of $10 \mathrm{nV}$ ).

The measurement system employs a set of four voltage followers $A_{1}, A_{2}, A_{3}$, and $A_{4}$. Those amplifiers are used to buffer bridge impedances, $Z_{1}, Z_{2}, Z_{3}$, and $Z_{4}$. The gain of each amplifier is very close to one. The estimated gain deviation is derived from the location of the pole in the open loop frequency characteristic provided by the manufacturer. The amplifiers used are Burr-Brown OPA627. For the amplifiers used as voltage followers, manufacturer specifications indicate that the gain depends on the voltage magnitude applied. This is very important in our case since the measured voltages differ from each other by $1 \mathrm{~V}$, nominally.

There is also a pair of differential amplifiers, $\mathrm{D}_{1}$ and $\mathrm{D}_{2}$, and a balance indicator. The differential amplifiers are connected to measure the difference of the applied voltages with the gain of two. The balance indicator used is a lock-in amplifier. The amplifiers are modeled using their open loop frequency characteristic. The manufacturer specifications suggest that the gain does depend on the voltage magnitude applied. The part used is Analog Devices AD8129/AD8130.

The paper will present a MATLAB simulation of the balancing process. First, a test bed is constructed to represent some level of unpredictability associated with the parts used and voltages applied. In order to measure the effects of gain changes, it is possible to inject a known voltage. The details of that operation are given in the following section.

\section{Test bed design}

The following parameters are created in order to test the simulations.

\section{Input voltage}

First, the voltages $\mathrm{V}_{1}, \mathrm{~V}_{2}, \mathrm{~V}_{3}$, and $\mathrm{V}_{4}$ are generated. Magnitude variation is set up to be 0.1 percent and phase variation is 0.01 percent. $V_{\text {nominal }}$ is assigned values $\left\{\begin{array}{llll}1 & 2 & 3 & 4\end{array}\right\}$ [V] in our case. The MATLAB function randn is used to generate noise using normally distributed random values.

$V=V_{n o \min a l}\left(1+\frac{0.1}{100}\right.$ randn $) e^{j 2 \pi\left(1+\frac{0.01}{100} r a n d n\right)} \quad$.

\footnotetext{
* In order to describe the procedures discussed in this paper, commercial products are identified. In no case does such identification imply recommendation or endorsement by the National Institute of Standards and Technology or that the materials or equipment specified are necessarily the best available for the purpose.
} 


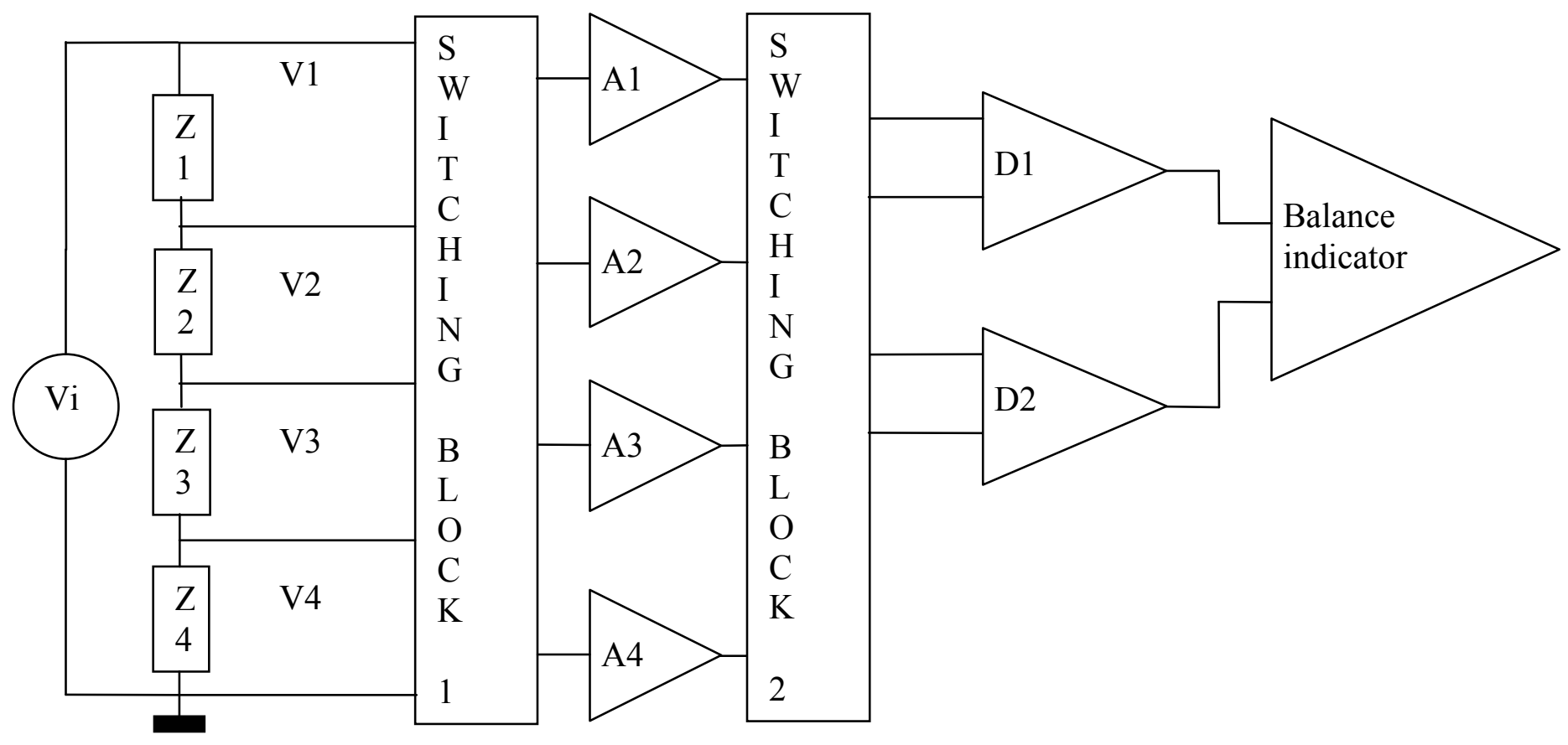

Fig. 1. Generalized system schematic.

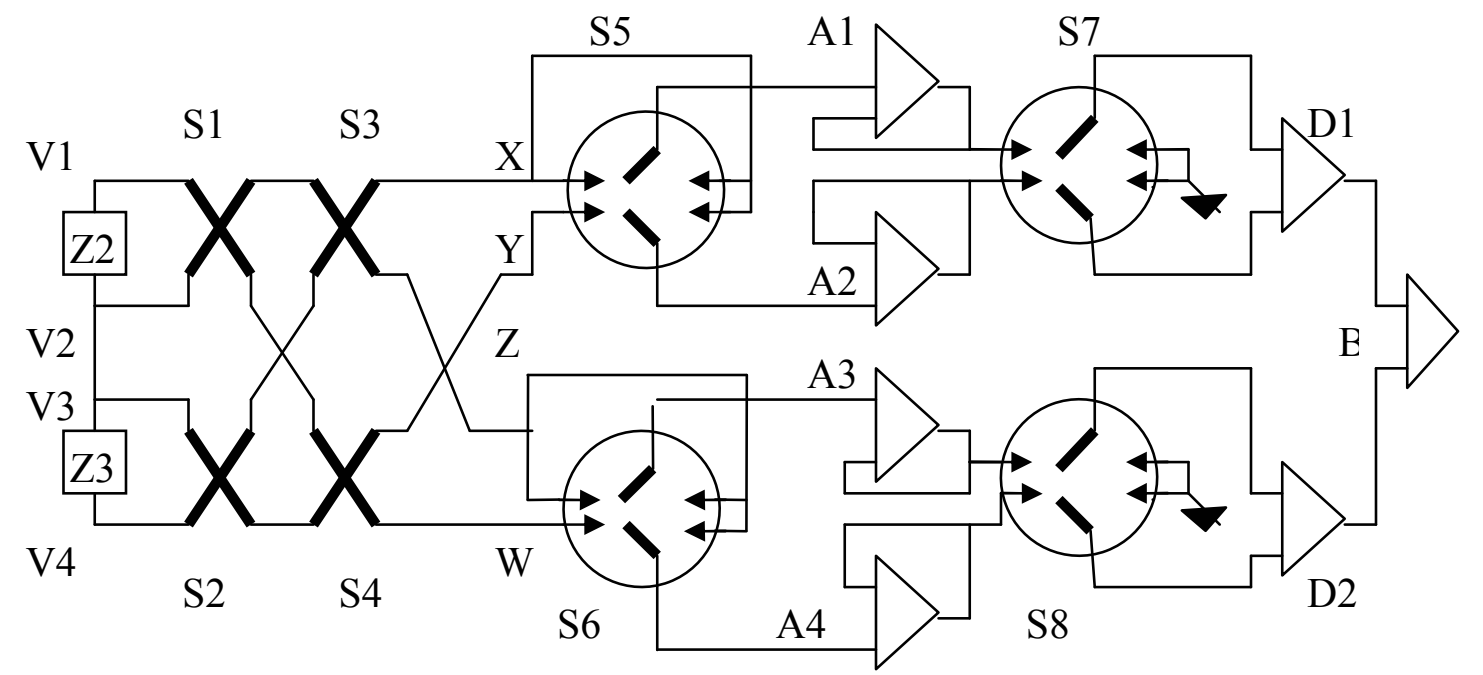

Fig. 2. Actual measurement system. 


\section{Amplifier gain}

Fig. 2 shows the actual measurement system and Table 1 shows some of the possible switch combinations.

Note on switch positions: Switches $\mathrm{S}_{1}, \mathrm{~S}_{2}, \mathrm{~S}_{3}$, and $\mathrm{S}_{4}$ have the strait position when the control signal is ' 1 ', and the crossed position when the control signal is '0'. Switches $\mathrm{S}_{5}, \mathrm{~S}_{6}, \mathrm{~S}_{7}$, and $\mathrm{S}_{8}$ have the left position when the control signal is ' 1 ' and the right position when the control signal is ' 0 '. In particular, switches $S_{7}$ and $\mathrm{S}_{8}$ are grounded when the control signal is ' 0 '.

Note on gain notation: $A_{n V m}$ means that voltage $V_{m}$ is applied to amplifier $n$. For example, $A_{2 V 1}$ means that voltage $V_{1}$ is applied to the amplifier $A_{2}$.

\begin{tabular}{|c|c|c|}
\hline $\begin{array}{l}\text { Switch set up } \\
\mathrm{S}_{1} \mathrm{~S}_{2} \mathrm{~S}_{3} \mathrm{~S}_{4} \mathrm{~S}_{5} \mathrm{~S}_{6} \mathrm{~S}_{7} \mathrm{~S}_{8}\end{array}$ & Intermediate voltages & $\mathrm{V}_{\text {balance }}$ \\
\hline $\begin{array}{lllllllll}1 & 1 & 1 & 1 & 0 & 1 & 1 & 0 \\
\end{array}$ & $\mathrm{X}=\mathrm{V}_{1} \mathrm{Y}=\mathrm{V}_{2} \mathrm{Z}=\mathrm{V}_{3} \mathrm{~W}=\mathrm{V}_{4}$ & $\mathrm{~V}_{\mathrm{det} 1}=\mathrm{V}_{1} \mathrm{~A}_{1 \mathrm{~V} 1^{-}}-\mathrm{V}_{1} \mathrm{~A}_{2 \mathrm{~V} 1}$ \\
\hline $\begin{array}{lllllll} & 1 & 0 & 1 & 1 & 0 \\
\end{array}$ & $\mathrm{X}=\mathrm{V}_{2} \mathrm{Y}=\mathrm{V}_{1} \mathrm{Z}=\mathrm{V}_{3} \mathrm{~W}=\mathrm{V}_{4}$ & $\mathrm{~V}_{\mathrm{det} 2}=\mathrm{V}_{2} \mathrm{~A}_{1 \mathrm{~V} 2}-\mathrm{V}_{2} \mathrm{~A}_{2 \mathrm{~V} 2}$ \\
\hline $\begin{array}{llllllll}1 & 1 & 0 & 0 & 1 & 0 & 0 & 1 \\
\end{array}$ & $\mathrm{X}=\mathrm{V}_{3} \mathrm{Y}=\mathrm{V}_{4} \mathrm{Z}=\mathrm{V}_{1} \mathrm{~W}=\mathrm{V}_{2}$ & $\mathrm{~V}_{\mathrm{det} 3}=\mathrm{V}_{1} \mathrm{~A}_{3 \mathrm{~V} 1}-\mathrm{V}_{1} \mathrm{~A}_{4 \mathrm{~V} 1}$ \\
\hline $\begin{array}{llllllll}0 & 1 & 0 & 0 & 1 & 0 & 0 & 1 \\
\end{array}$ & $\mathrm{X}=\mathrm{V}_{3} \quad \mathrm{Y}=\mathrm{V}_{4} \mathrm{Z}=\mathrm{V}_{2} \mathrm{~W}=\mathrm{V}_{1}$ & $\mathrm{~V}_{\operatorname{det} 4}=\mathrm{V}_{2} \mathrm{~A}_{3 \mathrm{~V} 2}-\mathrm{V}_{2} \mathrm{~A}_{4 \mathrm{~V} 2}$ \\
\hline 111 & $X=V_{1} Y=V_{2} Z=V_{3} W=V_{4}$ & $\mathrm{~V}_{\mathrm{det} 9}=\left(\mathrm{V}_{1} \mathrm{~A}_{1 \mathrm{~V} 1}-\mathrm{V}_{2} \mathrm{~A}_{2 \mathrm{~V} 2}\right)-\left(\mathrm{V}_{3} \mathrm{~A}_{3 \mathrm{~V} 3}-\mathrm{V}_{4} \mathrm{~A}_{4 \mathrm{~V} 4}\right)$ \\
\hline
\end{tabular}

Table 1. Switch positions.

The magnitude gain variation is set up to be 0.1 percent and the phase gain variation is set to 0.01 percent. We use the $A_{n V m}$ notation for the gain as in Table 1 .

$$
A_{n V m}=\left(1+\frac{0.1}{100} \text { randn }\right) e^{j 2 \pi\left(1+\frac{0.01}{100} \text { randn }\right)} \text {. }
$$

Let us assume some small variation in gain due to different voltages applied, so that

$$
D=\left(10^{-6} \text { randn }\right) e^{j 2 \pi\left(1+10^{-5} \text { randn }\right)} \text {. }
$$

Let us also scale this linearity with the voltage difference, so that

$$
A_{n V m}=A_{n V 1}+D\left(V_{1}-V_{m}\right) \text {. }
$$

Note that all of the gains are given relative to the voltage $\mathrm{V}_{1}$. This gives

$$
\begin{aligned}
& A_{1 V 2}=A_{1 V 1}+D\left(V_{1}-V_{2}\right), \\
& A_{2 V 2}=A_{2 V 1}+D\left(V_{1}-V_{2}\right), \\
& A_{3 V 3}=A_{3 V 1}+D\left(V_{1}-V_{3}\right) \text { and } \\
& A_{4 V 4}=A_{4 V 1}+D\left(V_{1}-V_{4}\right) .
\end{aligned}
$$




\section{Injection}

Let us create the first set of measurements related to voltage $V_{1}$ using all possible switching combinations:

$\mathrm{V}_{\text {det1 }}=\mathrm{V}_{1}\left(\mathrm{~A}_{1 \mathrm{~V} 1}-\mathrm{A}_{2 \mathrm{~V} 1}\right)$,

$\mathrm{V}_{\text {det3 }}=\mathrm{V}_{1}\left(\mathrm{~A}_{3 \mathrm{~V} 1}-\mathrm{A}_{4 \mathrm{~V} 1}\right)$,

$\mathrm{V}_{\text {det9 }}=\mathrm{V}_{1}\left(\mathrm{~A}_{1 \mathrm{~V} 1}-\mathrm{A}_{3 \mathrm{~V} 1}\right)$ and

$\mathrm{V}_{\text {det11 }}=\mathrm{V}_{1}\left(\mathrm{~A}_{2 \mathrm{~V} 1}-\mathrm{A}_{4 \mathrm{~V} 1}\right)$.

One of these equations is linearly dependent. We will neglect equation (10). Let us make one extra measurement using a known injection $\alpha$. This step is critical for the balancing algorithm since we are measuring the gain effect on a known injection. Practically, this injection is implemented using an injection transformer between switch, $\mathrm{S}_{7}$, and differential amplifier, D1, as well as between switch, $\mathrm{S}_{8}$, and differential amplifier, D2. This step is necessary in order to be able to express voltage gain products:

$\mathrm{V}^{\alpha}{ }_{\text {det } 1}=\mathrm{V}_{1} \mathrm{~A}_{1 \mathrm{~V} 1}-\alpha \mathrm{V}_{1} \mathrm{~A}_{1 \mathrm{~V} 1}-\mathrm{V}_{1} \mathrm{~A}_{2 \mathrm{~V} 1}=\mathrm{V}_{1}\left(\mathrm{~A}_{1 \mathrm{~V} 1}(1-\alpha)-\mathrm{A}_{2 \mathrm{~V} 1}\right)$.

Now we can form voltage gain products that depend only on the set of taken measurements:

$\mathrm{V}_{1} \mathrm{~A}_{1 \mathrm{~V} 1}=\frac{V_{\text {det1 }}-V^{\alpha}{ }_{\text {det1 }}}{\alpha}$,

$\mathrm{V}_{1} \mathrm{~A}_{2 \mathrm{~V} 1}=\frac{V_{\text {det1 } 1}-V^{\alpha}{ }_{\operatorname{det} 1}}{\alpha}-V_{\operatorname{det} 1}$,

$\mathrm{V}_{1} \mathrm{~A}_{3 \mathrm{~V} 1}=\frac{V_{\operatorname{det} 1}-V^{\alpha}{ }_{\operatorname{det} 1}}{\alpha}-V_{\operatorname{det} 9}$, and

$\mathrm{V}_{1} \mathrm{~A}_{4 \mathrm{~V} 1}=\frac{V_{\operatorname{det} 1}-V^{\alpha}{ }_{\operatorname{det} 1}}{\alpha}-V_{\operatorname{det} 1}-V_{\operatorname{det} 11}$.

These equations are calculated from known injections with initially measured gains (equations 9-13). A similar process can be determined for the remaining voltage gain products. The equations are given in Appendix 1.

This derivation concludes the test bed construction in which we created sets of measurements that will be used in generating the criterion for balance. This is a well-defined process that depends on the switching scheme and can be a very good exercise for students.

\section{Balance finding algorithm}

At this point we have the gain voltage products. The next step is to find the condition at which the voltage difference can be sensed. By manipulating switches, we can create one extra measurement:

$\mathrm{V}_{\text {det17 }}=\left(\mathrm{V}_{1} \mathrm{~A}_{1 \mathrm{~V} 1}-\mathrm{V}_{2} \mathrm{~A}_{2 \mathrm{~V} 2}\right)-\left(\mathrm{V}_{3} \mathrm{~A}_{3 \mathrm{~V} 3}-\mathrm{V}_{4} \mathrm{~A}_{4 \mathrm{~V} 4}\right)$. 
Let us use a slightly different representation for the gain expression:

$$
\begin{aligned}
& \mathrm{A}_{2 \mathrm{~V} 2}=\mathrm{A}_{1 \mathrm{~V} 1}+\Delta_{\mathrm{A}_{2 \mathrm{~V} 2}}, \\
& \mathrm{~A}_{3 \mathrm{~V} 3}=\mathrm{A}_{1 \mathrm{~V} 1}+\Delta_{\mathrm{A}_{3 \mathrm{~V} 3}} \text { and } \\
& \mathrm{A}_{4 \mathrm{~V} 4}=\mathrm{A}_{1 \mathrm{~V} 1}+\Delta_{\mathrm{A}_{4 \mathrm{~V} 4}} .
\end{aligned}
$$

The equations 19-21 allow us to rewrite equation (18) so that

$$
\mathrm{V}_{\text {det17 }}=\mathrm{A}_{1 \mathrm{~V} 1}\left(\mathrm{~V}_{1}-\mathrm{V}_{2}-\mathrm{V}_{3}+\mathrm{V}_{4}\right)-\mathrm{V}_{2} \Delta_{\mathrm{A}_{2 \mathrm{~V} 2}}-\mathrm{V}_{3} \Delta_{\mathrm{A}_{3 \mathrm{~V} 3}}+\mathrm{V}_{4} \Delta_{\mathrm{A}_{4 \mathrm{~V} 4}} .
$$

Let us use the notation

$$
\begin{aligned}
& \mathrm{A}_{1 \mathrm{~V} 1}\left(\mathrm{~V}_{1}-\mathrm{V}_{2}-\mathrm{V}_{3}+\mathrm{V}_{4}\right)=\mathrm{A}_{1 \mathrm{~V} 1} \mathrm{~V}_{1}-\mathrm{A}_{1 \mathrm{~V} 1} \mathrm{~V}_{2}-\mathrm{A}_{1 \mathrm{~V} 1} \mathrm{~V}_{3}+\mathrm{A}_{1 \mathrm{~V} 1} \mathrm{~V}_{4}=\text { BALANCE and } \\
& -\mathrm{V}_{2} \Delta_{\mathrm{A}_{2 \mathrm{~V} 2}}-\mathrm{V}_{3} \Delta_{\mathrm{A}_{3 \mathrm{~V}}}+\mathrm{V}_{4} \Delta_{\mathrm{A}_{4 V 4}}=\text { RESIDUE. }
\end{aligned}
$$

The balance algorithm has two steps. In the first step, the balance is estimated. The measurements associated with the gain voltage products will be used. Equations (14) and (5) are used for $\mathrm{V}_{1} \mathrm{~A}_{1 \mathrm{~V} 1}$.

$$
\begin{aligned}
& A_{1 V 2}=A_{1 V 1}+D\left(V_{1}-V_{2}\right), \\
& A_{1 V 3}=A_{1 V 1}+D\left(V_{1}-V_{3}\right) \text { and } \\
& A_{1 V 4}=A_{1 V 1}+D\left(V_{1}-V_{4}\right) .
\end{aligned}
$$

In order to find the other relevant products, $\mathrm{A}_{1 \mathrm{~V} 1} \mathrm{~V}_{2}, \mathrm{~A}_{1 \mathrm{~V} 1} \mathrm{~V}_{3}$, and $\mathrm{A}_{1 \mathrm{~V} 1} \mathrm{~V}_{4}$, we will use the following combinations of equations: (24) and (12), (25) and (A15) and (26) and (A24). The result is given by

$\mathrm{V}_{2} \mathrm{~A}_{1 \mathrm{~V} 1}=\frac{-V_{\operatorname{det} 2}+V^{\alpha}{ }_{\operatorname{det} 2}}{\alpha}+V_{\operatorname{det} 2}-D\left(V_{1}-V_{2}\right) V_{2}$,

$\mathrm{V}_{3} \mathrm{~A}_{1 \mathrm{~V} 1}=\frac{V_{\operatorname{det} 5}-V^{\alpha}{ }_{\text {det3 }}}{\alpha}+V_{\text {det13 }}-D\left(V_{1}-V_{3}\right) V_{3}$ and

$\mathrm{V}_{4} \mathrm{~A}_{1 \mathrm{~V} 1}=\frac{-V_{\operatorname{det} 6}+V_{\operatorname{det} 4}^{\alpha}}{\alpha}+V_{\operatorname{det} 6}+V_{\operatorname{det} 14}-D\left(V_{1}-V_{4}\right) V_{4}$.

In this solution, we only know the limits of the operational amplifier linearity, D. Also the voltages $V_{1}, V_{2}$ $\mathrm{V}_{3}$, and $\mathrm{V}_{4}$ are known only to the order of $1 \mathrm{mV}$. Let us assume that the amplifier does not change the gain due to the different voltage levels applied. This assumption simplifies the problem. Note that NL stands for no linearity errors.

$\mathrm{V}_{2} \mathrm{~A}_{1 \mathrm{~V} 1} N L=\frac{-V_{\operatorname{det} 2}+V^{\alpha}{ }_{\operatorname{det} 2}}{\alpha}+V_{\operatorname{det} 2}$,

$\mathrm{V}_{3} \mathrm{~A}_{1 \mathrm{~V} 1} N L=\frac{V_{\text {det } 5}-V^{\alpha}{ }_{\operatorname{det} 3}}{\alpha}+V_{\text {det13 }} \quad$ and 
$\mathrm{V}_{4} \mathrm{~A}_{1 \mathrm{~V} 1} N L=\frac{-V_{\operatorname{det} 6}+V^{\alpha} \operatorname{det} 4}{\alpha}+V_{\operatorname{det} 6}+V_{\operatorname{det} 14}$

Then the equation for the balance is simple:

$\frac{V_{\operatorname{det} 1}-V^{\alpha}{ }_{\operatorname{det} 1}}{\alpha}-\left(\frac{-V_{\operatorname{det} 2}+V^{\alpha}{ }_{\operatorname{det} 2}}{\alpha}+V_{\operatorname{det} 2}\right)-\left(\frac{V_{\operatorname{det} 5}-V_{\operatorname{det} 3}^{\alpha}}{\alpha}+V_{\operatorname{det} 13}\right)+\left(\frac{-V_{\operatorname{det} 6}+V_{\operatorname{det} 4}^{\alpha}}{\alpha}+V_{\operatorname{det} 6}+V_{\operatorname{det} 14}\right)=$ BALANCE

This clearly establishes the balancing algorithm. First, measure all of the required voltages listed in equation (33). Then measure the voltage $V_{\text {det17. }}$. This measurement will provide the necessary estimate for the residue. In the next iteration, an injection is applied: inj $=V_{\text {det17 }}$ - BALANCE (value from equation (33)) . In a few iterations the measurement resolution will allow the balance condition $V_{1}-V_{2}=V_{3}-V_{4}$ to be detected with acceptable uncertainty.

The presented algorithm is readily programmable using a high-level software package such as MATLAB. This task can be accomplished by students. The switching scheme is straightforward and can also be readily programmed. Simulating the measurement system response gives students good insight into system operation.

\section{Estimating the linearity of the operational amplifiers used in the project}

The subsequent discussion explores estimation of the linearity of the operational amplifiers used.

We will start by looking at the following ratios:

Ratio $_{1}=\frac{\frac{A_{1 V 1} V_{1}}{A_{1 V 2} V_{2}}}{\frac{A_{2 V 1} V_{1}}{A_{2 V 2} V_{2}}}, \quad$ Ratio $_{2}=\frac{\frac{A_{1 V 1} V_{1}}{A_{1 V 3} V_{3}}}{\frac{A_{3 V 1} V_{1}}{A_{3 V 3} V_{3}}} \quad$ and $\quad$ Ratio $_{3}=\frac{\frac{A_{1 V 1} V_{1}}{A_{1 V 4} V_{4}}}{\frac{A_{4 V 1} V_{1}}{A_{4 V 4} V_{4}}}$.

When the simulated measurements were substituted for the voltage gain products, the result was 1 and the deviation was on the order of $1 \times 10^{-9}$ (one part per billion).

For example:

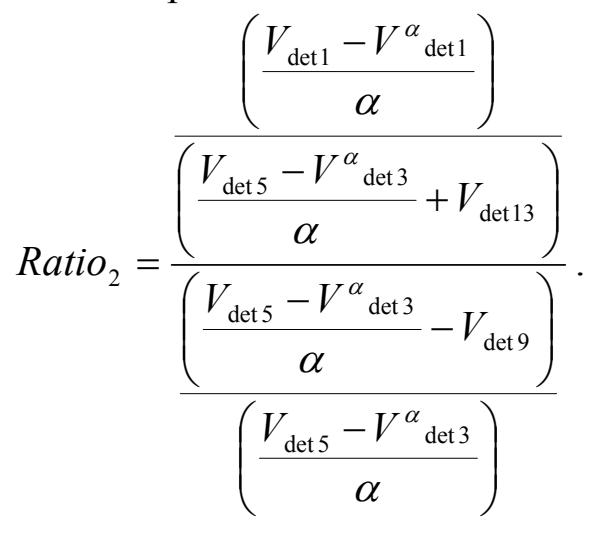


This prompted us to assume that we can use the gain ratios:

$A_{1 V 2}=\frac{A_{2 V 2} A_{1 V 1}}{A_{2 V 1}}, \quad A_{1 V 3}=\frac{A_{3 V 3} A_{1 V 1}}{A_{3 V 1}} \quad$ and $\quad A_{1 V 4}=\frac{A_{4 V 4} A_{1 V 1}}{A_{4 V 1}}$

Now let us assume that we can make the following set of measurements:

$\delta=V_{1}-V_{2}, \quad \zeta=V_{2}-V_{3} \quad$ and $\quad \rho=V_{3}-V_{4}$.

Using a lock-in amplifier, these measurements will be accurate to 0.1 percent. The voltage differences are on the order of $1 \mathrm{~V}$ so the lock-in resolution is on the order of $1 \mathrm{mV}$.

If we use the set given in (37) we can establish the relationship between the gains where all of the gains are related to the gain $\mathrm{A}_{1 \mathrm{~V} 1}$.

$$
\begin{aligned}
& \mathrm{V}_{1}-\mathrm{V}_{2}=\frac{V_{\text {det } 1}-V^{\alpha}{ }_{\operatorname{det} 1}}{\alpha \mathrm{A}_{1 \mathrm{~V} 1}}-\frac{V^{\alpha}{ }_{\operatorname{det} 2}-V_{\operatorname{det} 2}}{\alpha \mathrm{A}_{2 \mathrm{~V} 2}}=\delta \\
& A_{2 V 2}=\frac{\left(V^{\alpha}{ }_{\operatorname{det} 2}-V_{\operatorname{det} 2}\right) A_{1 V 1}}{V_{\operatorname{det} 1}-V_{\operatorname{det} 1}^{\alpha}-\delta \alpha A_{1 V 1}} \\
& A_{3 V 3}=\frac{\left(V_{\operatorname{det} 3}^{\alpha}-V_{\operatorname{det} 5}\right) A_{1 V 1}}{V_{\operatorname{det} 1}-V_{\operatorname{det} 1}^{\alpha}-(\delta+\zeta) \alpha A_{1 V 1}} \\
& A_{4 V 4}=\frac{\left(V_{\operatorname{det} 4}^{\alpha}-V_{\operatorname{det} 6}\right) A_{1 V 1}}{V_{\operatorname{det} 1}-V_{\operatorname{det} 1}^{\alpha}-(\delta+\zeta+\rho) \alpha A_{1 V 1}}
\end{aligned}
$$

So using the given ratios in equations (36), (39), (14), and (15), we find

$V_{2} A_{1 V 2} R=\frac{\left(\frac{\left(V_{\operatorname{det} 2}^{\alpha}-V_{\operatorname{det} 2}\right) A_{1 V 1}}{V_{\operatorname{det} 1}-V^{\alpha}{ }_{\operatorname{det} 1}-\delta \alpha A_{1 V 1}}\right) V_{2}\left(\frac{V_{\operatorname{det} 1}-V^{\alpha}{ }_{\operatorname{det} 1}}{\alpha}\right)}{\frac{V_{\operatorname{det} 1}-V^{\alpha}{ }_{\operatorname{det} 1}}{\alpha}-V_{\operatorname{det} 1}}=\frac{\left(A_{2 V 2} V_{2}\right)\left(V_{1} A_{1 V 1}\right)}{V_{1} A_{2 V 1}}$

The rest of the equations are:

$V_{3} A_{1 V 3} R=\frac{\left(\frac{\left(-V^{\alpha}{ }_{\operatorname{det} 3}+V_{\operatorname{det} 5}\right) A_{1 V 1}}{V_{\operatorname{det} 1}-V^{\alpha}{ }_{\operatorname{det} 1}-(\delta+\zeta) \alpha A_{1 V 1}}\right) V_{3}\left(\frac{V_{\operatorname{det} 1}-V_{\text {det } 1}^{\alpha}}{\alpha}\right)}{\frac{V_{\operatorname{det} 1}-V^{\alpha}{ }_{\operatorname{det} 1}}{\alpha}-V_{\operatorname{det} 9}}=\frac{\left(A_{3 V 3} V_{3}\right)\left(V_{1} A_{1 V 1}\right)}{V_{1} A_{3 V 1}}$ 
$V_{4} A_{1 V 4} R=\frac{\left(\frac{\left(V^{\alpha}{ }_{\operatorname{det} 4}-V_{\operatorname{det} 6}\right) A_{1 V 1}}{V_{\operatorname{det} 1}-V^{\alpha}{ }_{\operatorname{det} 1}-(\delta+\zeta+\rho) \alpha A_{1 V 1}}\right) V_{4}\left(\frac{V_{\operatorname{det} 1}-V^{\alpha}{ }_{\operatorname{det} 1}}{\alpha}\right)}{\frac{V_{\operatorname{det} 1}-V^{\alpha}{ }_{\operatorname{det} 1}}{\alpha}-V_{\operatorname{det} 1}-V_{\operatorname{det11}}}=\frac{\left(A_{4 V 4} V_{4}\right)\left(V_{1} A_{1 V 1}\right)}{V_{1} A_{4 V 1}}$

We can simplify these equations to

$C_{1 V 2}=\frac{\left(V^{\alpha}{ }_{\operatorname{det} 2}-V_{\operatorname{det} 2}\right)\left(\frac{V_{\operatorname{det} 1}-V^{\alpha}{ }_{\operatorname{det} 1}}{\alpha}\right)}{\frac{V_{\operatorname{det} 1}-V^{\alpha}{ }_{\operatorname{det} 1}}{\alpha}-V_{\operatorname{det} 1}}$
$C_{1 V 3}=\frac{\left(-V_{\operatorname{det} 3}^{\alpha}+V_{\operatorname{det} 5}\right)\left(\frac{V_{\operatorname{det} 1}-V^{\alpha}{ }_{\operatorname{det} 1}}{\alpha}\right)}{\frac{V_{\operatorname{det} 1}-V^{\alpha}{ }_{\operatorname{det} 1}}{\alpha}-V_{\operatorname{det} 9}}$
$C_{1 V 4}=\frac{\left(V_{\operatorname{det} 4}^{\alpha}+V_{\operatorname{det} 6}\right)\left(\frac{V_{\operatorname{det} 1}-V^{\alpha}{ }_{\operatorname{det} 1}}{\alpha}\right)}{\frac{V_{\operatorname{det1}}-V^{\alpha}{ }_{\operatorname{det} 1}}{\alpha}-V_{\operatorname{det} 9}-V_{\operatorname{det} 11}}$

$V_{2} A_{1 V 2} R=V_{2} C_{1 V 2} \frac{A_{1 V 1}}{V_{\operatorname{det} 1}-V^{\alpha}{ }_{\operatorname{det} 1}-\delta \alpha A_{1 V 1}}$

$V_{3} A_{1 V 3} R=V_{3} C_{1 V 3} \frac{A_{1 V 1}}{V_{\operatorname{det} 1}-V^{\alpha}{ }_{\operatorname{det} 1}-(\delta+\zeta) \alpha A_{1 V 1}}$

$V_{4} A_{1 V 4} R=V_{4} C_{1 V 4} \frac{A_{1 V 1}}{V_{\operatorname{det} 1}-V^{\alpha}{ }_{\operatorname{det} 1}-(\delta+\zeta+\rho) \alpha A_{1 V 1}}$

We can expand this non linear equations using Taylor's expansion around $\mathrm{A}_{1 \mathrm{~V} v} \approx 1$. Only the first order is used.

$\frac{\partial\left(V_{2} A_{1 V 2} R\right)}{\partial A_{1 V 1}}=V_{2} C_{1 V 2} \frac{\left(V_{\operatorname{det} 1}-V^{\alpha}{ }_{\operatorname{det} 1}-\delta \alpha A_{1 V 1}\right)+\alpha \delta A_{1 V 1}}{\left(V_{\operatorname{det} 1}-V^{\alpha}{ }_{\operatorname{det} 1}-\delta \alpha A_{1 V 1}\right)^{2}}=V_{2} C_{1 V 2} \frac{V_{\operatorname{det} 1}-V^{\alpha}{ }_{\operatorname{det} 1}}{\left(V_{\operatorname{det} 1}-V^{\alpha}{ }_{\operatorname{det} 1}-\delta \alpha A_{1 V 1}\right)^{2}}$ 


$$
\begin{aligned}
& V_{2} A_{1 V 2} e=\left.V_{2} A_{1 V 2} R\right|_{A_{1 V 1}=1}+\left.\frac{\partial\left(V_{2} A_{1 V 2} R\right)}{\partial A_{1 V 1}}\right|_{A_{1 V 1}=1}\left(A_{1 V 1}-1\right) \\
& V_{2} A_{1 V 2} e=V_{2} C_{1 V 2}\left(\frac{1}{V_{\operatorname{det} 1}-V^{\alpha}{ }_{\operatorname{det} 1}-\delta \alpha}+\frac{V_{\operatorname{det} 1}-V^{\alpha}{ }_{\operatorname{det} 1}}{\left(V_{\operatorname{det} 1}-V^{\alpha}{ }_{\operatorname{det} 1}-\delta \alpha\right)^{2}}\left(A_{1 V 1}-1\right)\right) \\
& V_{2} A_{1 V 2} e=V_{2} C_{1 V 2} \frac{V_{\operatorname{det} 1}-V^{\alpha}{ }_{\operatorname{det} 1}-\delta \alpha+\left(V_{\operatorname{det} 1}-V^{\alpha}{ }_{\operatorname{det} 1}\right) A_{1 V 1}-\left(V_{\operatorname{det} 1}-V^{\alpha}{ }_{\operatorname{det} 1}\right)}{\left(V_{\operatorname{det} 1}-V_{\operatorname{det} 1}^{\alpha}-\delta \alpha\right)^{2}} \\
& V_{2} A_{1 V 2} e=V_{2} C_{1 V 2} \frac{\left(V_{\operatorname{det} 1}-V^{\alpha}{ }_{\operatorname{det} 1}\right) A_{1 V 1}-\delta \alpha}{\left(V_{\operatorname{det} 1}-V^{\alpha}{ }_{\operatorname{det} 1}-\delta \alpha\right)^{2}} \\
& V_{3} A_{1 V 3} e=V_{3} C_{1 V 3} \frac{\left(V_{\operatorname{det} 1}-V_{\operatorname{det} 1}^{\alpha}\right) A_{1 V 1}-(\delta+\zeta) \alpha}{\left(V_{\operatorname{det} 1}-V^{\alpha}{ }_{\operatorname{det} 1}-(\delta+\zeta) \alpha\right)^{2}} \\
& V_{4} A_{1 V 4} e=V_{4} C_{1 V 4} \frac{\left(V_{\operatorname{det} 1}-V^{\alpha}{ }_{\operatorname{det} 1}\right) A_{1 V 1}-(\delta+\zeta+\rho) \alpha}{\left(V_{\operatorname{det} 1}-V^{\alpha}{ }_{\operatorname{det} 1}-(\delta+\zeta+\rho) \alpha\right)^{2}}
\end{aligned}
$$

Recall that the goal of our algorithm is to estimate the balance $A_{1 V 1} V_{1}-A_{1 V 1} V_{2}-A_{1 V 1} V_{3}+A_{1 V 1} V_{4}$.

We can measure the voltages expressed using equations (52)-(54). The measurements are given by (A6), (A15), and (A24).

$$
\begin{aligned}
& V_{2} A_{1 V 1}=\frac{\frac{\left(V_{\text {det } 1}-V^{\alpha}{ }_{\text {det } 1}-\delta \alpha\right)^{2}\left(V_{2} A_{1 V 2} e\right)}{C_{1 V 2}}+\delta \alpha V_{2}}{\left(V_{\operatorname{det} 1}-V^{\alpha}{ }_{\text {det1 } 1}\right)} \\
& V_{3} A_{1 V 1}=\frac{\frac{\left(V_{\operatorname{det} 1}-V^{\alpha}{ }_{\operatorname{det} 1}-(\delta+\zeta) \alpha\right)^{2}\left(V_{3} A_{1 V 3} e\right)}{C_{1 V 3}}+(\delta+\zeta) \alpha V_{3}}{\left(V_{\operatorname{det} 1}-V_{\operatorname{det} 1}^{\alpha}\right)} \\
& V_{4} A_{1 V 1}=\frac{\frac{\left(V_{\text {det1 }}-V_{\text {det1 }}^{\alpha}-(\delta+\zeta+\rho) \alpha\right)^{2}\left(V_{4} A_{1 V 4} e\right)}{C_{1 V 4}}+(\delta+\zeta+\rho) \alpha V_{4}}{\left(V_{\text {det1 }}-V_{\text {det1 }}^{\alpha}\right)}
\end{aligned}
$$

The measurement of $\mathrm{A}_{1 \mathrm{~V} 1} \mathrm{~V}_{1}$ is given by (14). The rest of the voltage-gain products are given by (55)-(57). All of the measurements are available except the values for $\mathrm{V}_{2}, \mathrm{~V}_{3}$, and $\mathrm{V}_{4}$. The nominal values can be used. This estimate of the voltage-gain products is only as good as we can measure delta, zeta, and ro $(\delta, \zeta, \rho)$.

It is important to note that the equations presented used only one set of switch positions. It is possible to derive a similar set of equations for the equivalent sets of switch positions and in that way test the validity 
of the proposed algorithm. Also, if all of the redundant combinations were to be developed, then the average values of the estimates could be used, and in that sense, improve the accuracy of the proposed algorithm. Producing the alternative sets of equations is an adequate challenge for students skillful in programming.

\section{Conclusions}

This paper presented a measurement system that measures voltage balance. In the field of precise measurements, it is often desired to balance voltage differences. The proposed algorithm is novel. This is ongoing research and the experiment is in the process of construction to test the proposed algorithm.

The derivations are presented that provide the basis for finding the balance. The MATLAB simulation is provided. This is an appropriate project for engineering students. Since the mathematical model is well described, students are well equipped to write software simulations to test the derived equations. It is also very beneficial for students to implement the model in hardware.

\section{References}

[1] R. D. Cutkosky: "Four -Terminal-Pair networks as Precision Admittance and Impedance Standards," IEEE Trans. On Comm. And Electronics, Vol 70, pp19-22, 1964.

[2] R. D. Cutkosky: "Techniques for Comparing Four-Terminal-Pair Admittance Standards," Journal of Research of the NBS, Vol 74C, pp63-77, 1970.

Appendix 1.

Derivations for voltage $V_{2}$ :

$$
\begin{aligned}
& \mathrm{V}_{\text {det2 }}=\mathrm{V}_{2}\left(\mathrm{~A}_{1 \mathrm{~V} 2}-\mathrm{A}_{2 \mathrm{~V} 2}\right) \\
& \mathrm{V}_{\text {det4 }}=\mathrm{V}_{2}\left(\mathrm{~A}_{3 \mathrm{~V} 2}-\mathrm{A}_{4 \mathrm{~V} 2}\right) \\
& \mathrm{V}_{\text {det10 }}=\mathrm{V}_{2}\left(\mathrm{~A}_{1 \mathrm{~V} 2}-\mathrm{A}_{3 \mathrm{~V} 2}\right) \\
& \mathrm{V}_{\text {det12 }}=\mathrm{V}_{2}\left(\mathrm{~A}_{2 \mathrm{~V} 2}-\mathrm{A}_{4 \mathrm{~V} 2}\right) \\
& \mathrm{V}^{\alpha}{ }_{\text {det2 }}=\mathrm{V}_{2} \mathrm{~A}_{1 \mathrm{~V} 2}-\alpha \mathrm{V}_{2} \mathrm{~A}_{2 \mathrm{~V} 2}-\mathrm{V}_{2} \mathrm{~A}_{2 \mathrm{~V} 2}=\mathrm{V}_{2}\left(\mathrm{~A}_{1 \mathrm{~V} 2}(1-\alpha)-\mathrm{A}_{2 \mathrm{~V} 2}\right) \\
& \mathrm{V}_{2} \mathrm{~A}_{1 \mathrm{~V} 2}=\frac{-V_{\operatorname{det} 2}+V^{\alpha}{ }_{\operatorname{det} 2}}{\alpha}+V_{\operatorname{det} 2} \\
& \mathrm{~V}_{2} \mathrm{~A}_{2 \mathrm{~V} 2}=\frac{-V_{\operatorname{det} 2}+V_{\operatorname{det} 2}^{\alpha}}{\alpha} \\
& \mathrm{V}_{2} \mathrm{~A}_{3 \mathrm{~V} 2}=\frac{-V_{\operatorname{det} 2}+V^{\alpha}{ }_{\operatorname{det} 2}}{\alpha}+V_{\operatorname{det} 2}-V_{\operatorname{det} 10} \\
& \mathrm{~V}_{2} \mathrm{~A}_{4 \mathrm{~V} 2}=\frac{-V_{\operatorname{det} 2}+V^{\alpha}{ }_{\operatorname{det} 2}}{\alpha}+V_{\operatorname{det} 12}
\end{aligned}
$$

Derivations for the voltage $V_{3}$ :

$\mathrm{V}_{\mathrm{det} 5}=\mathrm{V}_{3}\left(\mathrm{~A}_{3 \mathrm{~V} 3}-\mathrm{A}_{4 \mathrm{~V} 3}\right)$ 


$$
\begin{aligned}
& \mathrm{V}_{\text {det7 }}=\mathrm{V}_{3}\left(\mathrm{~A}_{1 \mathrm{~V} 3}-\mathrm{A}_{2 \mathrm{~V} 3}\right) \\
& \mathrm{V}_{\text {det13 }}=\mathrm{V}_{3}\left(\mathrm{~A}_{1 \mathrm{~V} 3}-\mathrm{A}_{3 \mathrm{~V} 3}\right) \\
& \mathrm{V}_{\mathrm{det} 15}=\mathrm{V}_{3}\left(\mathrm{~A}_{2 \mathrm{~V} 3}-\mathrm{A}_{4 \mathrm{~V} 3}\right) \\
& \mathrm{V}^{\alpha}{ }_{\text {det } 3}=\mathrm{V}_{3} \mathrm{~A}_{3 \mathrm{~V} 3}-\alpha \mathrm{V}_{3} \mathrm{~A}_{3 \mathrm{~V} 3}-\mathrm{V}_{3} \mathrm{~A}_{4 \mathrm{~V} 3}=\mathrm{V}_{3}\left(\mathrm{~A}_{3 \mathrm{~V} 3}(1-\alpha)-\mathrm{A}_{4 \mathrm{~V} 3}\right) \\
& \mathrm{V}_{3} \mathrm{~A}_{1 \mathrm{~V} 3}=\frac{V_{\operatorname{det} 5}-V^{\alpha}{ }_{\operatorname{det} 3}}{\alpha}+V_{\operatorname{det} 13} \\
& \mathrm{~V}_{3} \mathrm{~A}_{2 \mathrm{~V} 3}=\frac{V_{\operatorname{det} 5}-V^{\alpha}{ }_{\operatorname{det} 3}}{\alpha}-V_{\operatorname{det} 5}+V_{\operatorname{det} 15} \\
& \mathrm{~V}_{3} \mathrm{~A}_{3 \mathrm{~V} 3}=\frac{V_{\text {det } 5}-V^{\alpha}{ }_{\operatorname{det} 3}}{\alpha} \\
& \mathrm{V}_{3} \mathrm{~A}_{4 \mathrm{~V} 3}=\frac{V_{\operatorname{det} 5}-V^{\alpha}{ }_{\operatorname{det} 3}}{\alpha}-V_{\operatorname{det} 5} \\
& \mathrm{~V}_{\text {det6 }}=\mathrm{V}_{4}\left(\mathrm{~A}_{3 \mathrm{~V} 4}-\mathrm{A}_{4 \mathrm{~V} 4}\right) \\
& \mathrm{V}_{\text {det8 }}=\mathrm{V}_{4}\left(\mathrm{~A}_{1 \mathrm{~V} 4}-\mathrm{A}_{2 \mathrm{~V} 4}\right) \\
& \mathrm{V}_{\text {det14 }}=\mathrm{V}_{4}\left(\mathrm{~A}_{1 \mathrm{~V} 4}-\mathrm{A}_{3 \mathrm{~V} 4}\right) \\
& \mathrm{V}_{\text {det16 }}=\mathrm{V}_{4}\left(\mathrm{~A}_{2 \mathrm{~V} 4}-\mathrm{A}_{3 \mathrm{~V} 4}\right) \\
& \mathrm{V}_{\text {det } 4}^{\alpha}=\mathrm{V}_{4} \mathrm{~A}_{3 \mathrm{~V} 4}-\alpha \mathrm{V}_{4} \mathrm{~A}_{3 \mathrm{~V} 4}-\mathrm{V}_{4} \mathrm{~A}_{4 \mathrm{~V} 4}=\mathrm{V}_{4}\left(\mathrm{~A}_{3 \mathrm{~V} 4}(1-\alpha)-\mathrm{A}_{4 \mathrm{~V} 4}\right) \\
& \mathrm{V}_{4} \mathrm{~A}_{1 \mathrm{~V} 4}=\frac{-V_{\operatorname{det} 6}-V^{\alpha}{ }_{\operatorname{det} 4}}{\alpha}+V_{\operatorname{det} 6}+V_{\operatorname{det} 14} \\
& \mathrm{~V}_{4} \mathrm{~A}_{2 \mathrm{~V} 4}=\frac{-V_{\operatorname{det} 6}-V^{\alpha}{ }_{\operatorname{det} 4}}{\alpha}+V_{\operatorname{det} 16} \\
& \mathrm{~V}_{4} \mathrm{~A}_{3 \mathrm{~V} 4}=\frac{-V_{\operatorname{det} 6}-V^{\alpha}{ }_{\operatorname{det} 4}}{\alpha}+V_{\operatorname{det} 6} \\
& \mathrm{~V}_{4} \mathrm{~A}_{3 \mathrm{~V} 4}=\frac{-V_{\operatorname{det} 6}-V^{\alpha}{ }_{\operatorname{det} 4}}{\alpha}
\end{aligned}
$$

0
00
0
0
$\overrightarrow{0}$
0
0
0
$\vec{N}$ 